\title{
Useful Simulation Tool for Induction Generators Used In Wind Power Plants
}

\author{
Loránd SZABÓ, Károly Ágoston BIRÓ, Cosmina NICULA, Florin JURCA \\ Department of Electrical Machines, Technical University of Cluj \\ P.O. Box 358, 400750 Cluj, Romania \\ E-mail: Lorand.Szabo@mae.utcluj.ro
}

\begin{abstract}
Electric energy generated by wind power plants is the fastest developing and most promising renewable energy source in Europe. Due to the advantages of power electronics wind energy conversion systems equipped with doubly fed induction generators for variable speed wind turbines are one of the most efficient configurations for wind energy conversion. The mathematical model and the simulation programs for such machines to be presented in the paper can help the understanding in this field and can be of real interest for all specialists involved in wind energy exploitation.
\end{abstract}

Index Terms - wind energy, doubly fed induction generator, mathematical model, simulation.

\section{INTRODUCTION}

The wind is a free, clean, and inexhaustible energy source. The kinetic energy of the wind can be changed into other forms of energy, mechanical or electrical. It has served mankind well for many centuries by propelling ships and driving wind turbines to grind grain and pump water.

Since the end of the $19^{\text {th }}$ century the wind power was also used to generate electricity. The pioneer in this field was Charles F. Brush (1849-1929), one of the founders of the American electrical industry, an inventive person holding several patents in the field of electricity generation. In 1888 he built the first automatically operating wind turbine for electricity generation. At that time it was a giant with a rotor diameter of $17 \mathrm{~m}$ and 144 rotor blades made of cedar wood (see Fig. 1) [1].

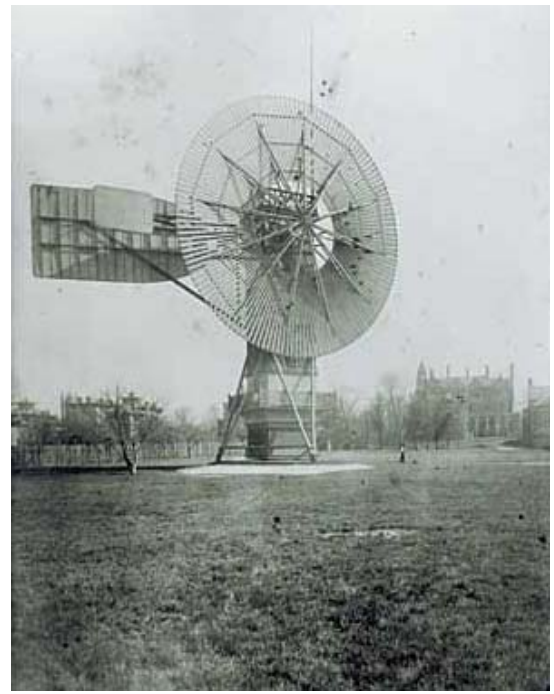

Fig. 1. The first wind turbine built in 1888 [1]
The turbine ran for 20 years and charged the batteries in the cellar of his mansion. Despite the size of the turbine, the generator had only $12 \mathrm{~kW}$ power, because that type of slowly rotating wind turbines of the American wind rose type did not have high efficiency.

The Danish Poul la Cour (1846-1908), another pioneer of electricity generating wind turbines, later discovered that fast rotating wind turbines with few rotor blades are more efficient for electricity production than the slow moving ones. The picture of his first test wind turbines built up in 1897 in Askov (Denmark) is given in Fig. 2 [2].

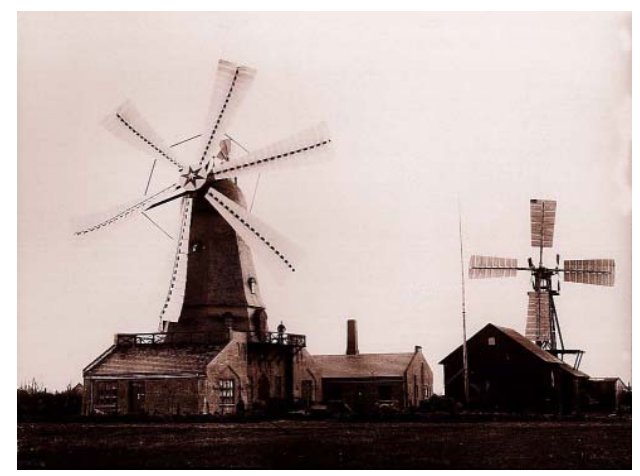

Fig. 2. The test wind turbines of La Cour [2]

The general interest in wind power lagged, however, when cheap and plentiful petroleum products became available mainly after World War II. The high capital costs and the uncertainty of the wind placed wind power at an economic disadvantage until the petroleum embargo from 1973. Since then people began to realize that the world's oil supplies would not last forever and that remaining supplies should be conserved for the petrochemical industry [3].

In the last decades everybody understood that only new and renewable energy sources can guarantee a sustainable power production in the future for the mankind. Our future life on the Earth will be largely determined by how the required energy will be generated and how the technological innovation will be applied. The renewable energy sources surely will have a strong transformative effect on the entire society in the coming decades. By virtually all accounts, renewable energy resources will be an increasingly important part of the power generation mix over the next several decades.

The clean technologies help reduce global carbon emissions, but they also add some much-needed 
flexibility to the energy resource mix by decreasing the dependence on limited reserves of fossil fuels.

Wind power has become the world's fastest growing energy source in the last part of the $20^{\text {th }}$ century and has maintained this status until now.

The total installed wind power capacity round the world at the end of 2006 stands over 74 GW. Only three countries share over the $59 \%$ of the total market: Germany $27.8 \%$, Spain $15.6 \%$ and US $15.6 \%$. These countries together have $43.84 \mathrm{GW}$ installed capacity. In 2006 only in the EU near 7.6 GW of wind power capacity was installed, worth over 9 billion $€$. This means an increase of $23 \%$ compared to 2005 [4], [5].

Romania is between the rearguards in Europe, having only $3 \mathrm{MW}$ of installed wind power capacity. Hence a lot thing can be done here in this field.

Due to this major interest for wind energy power plants intensive researches are done in numerous research centers all around the world. Hence any new results which contribute to the better understanding in this field could be of real interest for all the specialists.

\section{The DOUBLy Fed INDUCTION GENERATOR}

The most efficient solution for wind power plants is to use variable speed generators for electrical energy producing purposes [6]. There are several advantages of using such generators [7]. They can reduce mechanical stresses by storing the energy from wind gust in the mechanical inertia of the turbine, creating a sort of "elasticity" that reduces torque pulsations and improve the power quality. The system efficiency can be slightly improved by adjusting the turbine speed to maximize output power. The applied converters can also supply reactive power to the grid if the converters are rated for this purpose [8].

There are several types of adjustable speed generators used for such purposes [9]. The most common one is the doubly fed induction generator. Practically the stator of the machine is connected directly, or through a threephase transformer to the grid. The rotor windings are coupled by slip rings to the same grid via a four quadrant ac-to-ac converter setup as shown in Fig. 3 [10].

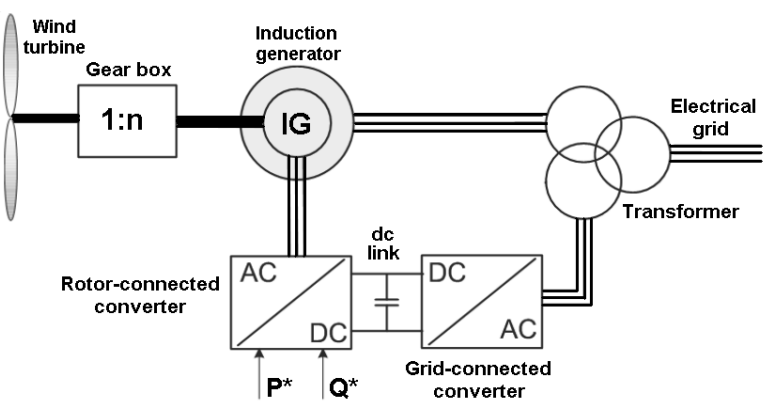

Fig. 3. The generator and converter setup used in wind power plants

The power that goes through the rotor of the induction generator depends on the slip. At the same time the power from the rotor is not wasted as in the case of induction machines with external variable rotor resistance. But it is fed to the grid, so varying the slip of the generator doesn't lower the efficiency any more.

The system needs a converter, and unfortunately also a sophisticated control system adjusting the slip to the given rotor speed. But the overall system efficiency is improved in comparison with fixed-speed generators.

The use of doubly fed induction generators for variable speed wind turbines offers also other advantages regarding the power electronic devices connected together [11]. The converter general cost is reduced because low converter power required. The converter has to deal only with approximately $25 \%$ of the total power of the generator because the main part of the energy passes from the stator directly to the grid. Therefore the required converter can be rated at a quarter of the total system power [12]. Also the costs of the converter filters and EMI filters are lower. The power-factor control can be implemented at lower cost, because the four-quadrant converter together with the induction machine basically operates similar to a synchronous generator. Hence the converter has to provide only the excitation energy. An other important advantage of the above presented scheme is that the four-quadrant converter in the rotor circuit enables decoupled control of active and reactive power of the generator.

\section{The Mathematical Model Of The Doubly Fed INDUCTION GENERATOR}

In general terms simulations are helpful in gaining insights to the dynamic behavior of any electrical drive system. They offer a fast and economical means by which they can conduct studies to learn more about these components [13].

The main goal of our research was to study the decoupled control of active and reactive power in wind power plants having doubly fed induction generators. This practically could not be performed without high performance simulation programs.

The first step towards the dynamic simulations was to build up the mathematical model of the doubly fed induction generator.

The widely used $d q$ reference frame was chosen to model the generator. In this case both the three-phased stator and rotor symmetrical windings are transformed in orthogonal two axis systems upon Park's transformation (as shown in Fig. 4)

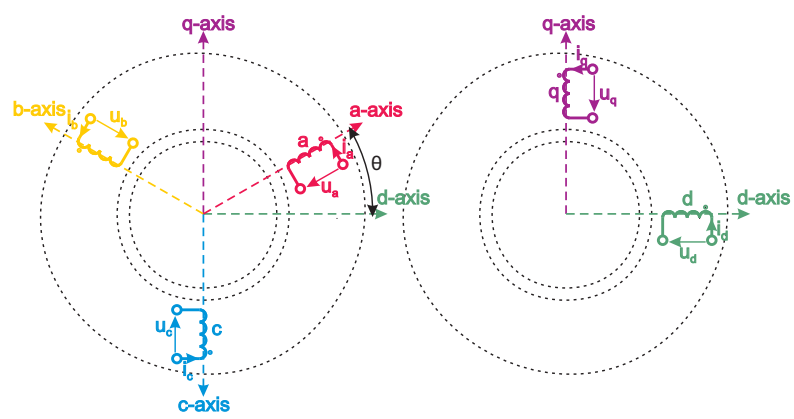

Fig. 4. The $a b c$ to $d q$ system transformation 
Hence the model machine has only 4 windings (two on the stator and two on the rotor) in quadrature. The fixed reference frame was selected for writing the equations. The angular speed of the reference frame in this case will be:

$$
\omega_{c}=0
$$

For the stator windings the generator convention will be used, and for rotor windings the load one [14]. The saturation effect of the magnetic cores also will be taken into account. Using the above conditions the following set of voltage equations results for the four windings:

$$
\begin{gathered}
u_{d}=-R_{s} i_{d}-\frac{d \lambda_{d}}{d t} ; u_{q}=-R_{s} i_{q}-\frac{d \lambda_{q}}{d t} \\
u_{D}=R_{r} i_{D}+\frac{d \lambda_{D}}{d t}+\omega \lambda_{Q} ; u_{Q}=R_{r} i_{Q}+\frac{d \lambda_{Q}}{d t}-\omega \lambda_{D}
\end{gathered}
$$

where $u$ is the voltage, $R$ the resistance, $i$ the current, $\omega$ the rotor electrical angular velocity, and $\lambda$ is the flux linkage. The $d$ and $q$ indices indicate the direct and quadrature axis components. With uppercase are marked the rotor quantities The $s$ and $r$ indices refers to the stator and rotor quantities, respectively. It should be mentioned that all the rotor quantities are referred to the stator of the machine.

To be able to solve the problem another set of equations is required, the flux-current equations, written also for the four windings:

$$
\begin{aligned}
& \lambda_{d}=L_{s \sigma} i_{d}+M\left(i_{d}+i_{D}\right) ; \lambda_{q}=L_{s \sigma} i_{q}+M\left(i_{q}+i_{Q}\right) \\
& \lambda_{D}=L_{r \sigma} i_{D}+M\left(i_{d}+i_{D}\right) ; \lambda_{Q}=L_{r \sigma} i_{Q}+M\left(i_{q}+i_{Q}\right)(5)
\end{aligned}
$$

where $L_{s \sigma}$ and $L_{r \sigma}$ are the leakage inductances, respectively $M=M_{d}=M_{q}$ is the main magnetizing inductance.

The mathematical model of the generator must be completed by to equations due to the load connected on its terminals:

$$
u_{d}=R_{l} i_{l d}+L_{l} \frac{d i_{l_{d}}}{d t} ; u_{q}=R_{l} i_{l_{q}}+L_{l} \frac{d i_{l_{q}}}{d t}
$$

where $R_{l}$ and $L_{l}$ are the resistance and inductance of the load, respectively $i_{l_{d}}$ and $i_{l_{q}}$ are the two orthogonal components of the load current.

$$
\begin{gathered}
\frac{d i_{d}}{d t}=\frac{-u_{d}\left(L_{r \sigma}+M_{t}\right)-M_{t} u_{D}-R_{s}\left(L_{r \sigma}+M_{t}\right) i_{d}+\omega M M_{t} i_{q}+R_{r} M_{t} i_{D}+\omega M_{t}\left(L_{r \sigma}+M\right) i_{Q}}{L_{s \sigma} L_{r \sigma}+L_{s \sigma} M+L_{r \sigma} M} \\
\frac{d i_{q}}{d t}=\frac{-u_{q}\left(L_{r \sigma}+M_{t}\right)-M_{t} u_{Q}-\omega M M_{t} i_{d}-R_{s}\left(L_{r \sigma}+M_{t}\right) i_{q}-\omega M_{t}\left(L_{r \sigma}+M\right) i_{D}+R_{r} M_{t} i_{Q}}{L_{s \sigma} L_{r \sigma}+L_{s \sigma} M+L_{r \sigma} M} \\
\frac{d i_{D}}{d t}=\frac{u_{d} M_{t}+\left(L_{s \sigma}+M_{t}\right) u_{D}+R_{s} M_{t} i_{d}-\omega M\left(L_{s \sigma}+M_{t}\right) i_{q}-R_{r}\left(L_{s \sigma}+M_{t}\right) i_{D}-\omega\left(L_{S \sigma}+M_{t}\right)\left(L_{R \sigma}+M\right) i_{Q}}{L_{s \sigma} L_{r \sigma}+L_{s \sigma} M+L_{r \sigma} M} \\
\frac{d i_{Q}}{d t}=\frac{u_{q} M_{t}+\left(L_{s \sigma}+M_{t}\right) u_{Q}+\omega M\left(L_{s \sigma}+M_{t}\right) i_{d}+R_{s} M_{t} i_{q}+\omega\left(L_{r \sigma}+M\right)\left(L_{s \sigma}+M_{t}\right) i_{D}-R_{r}\left(L_{s \sigma}+M_{t}\right) i_{Q}}{L_{s \sigma} L_{r \sigma}+L_{s \sigma} M+L_{r \sigma} M}
\end{gathered}
$$


Equations (11) $\div(14)$ together with the equations of the load (6) form together the mathematical model of the doubly fed induction generator, which was used in our simulations.

\section{Simulating Doubly Fed Induction Generators USED IN WIND POWER PLANTS}

Using the above presented mathematical model of the doubly fed induction generator the simulation program was built up is the combined MATLAB ${ }^{\circledR} /$ SIMULINK $^{\circledR}$ environment, one of the best choices to simulate complex dynamic systems.

For easy understanding and using of the simulation program was built up modularly, using several sub-systems. In the framework of the simulation program there are several switches back and forth between simulation in SIMULINK ${ }^{\circledR}$, respectively computation and visualization in MATLAB $^{\circledR}$, taking the full advantages of both programs.

The main window of the simulation program is given in Fig. 6.

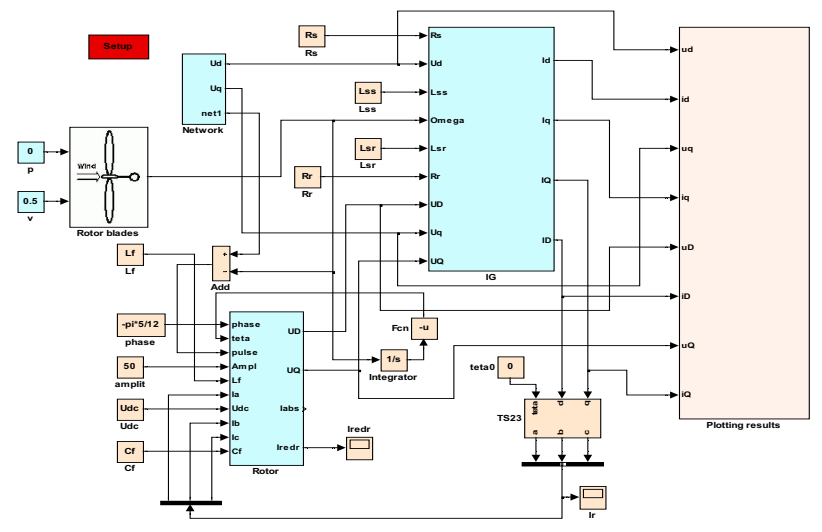

Fig. 6. The main window of the simulation program
Due to the lack of space here the subsystems of the model cannot be presented in detail.

All the data regarding the electrical energy generation system is loaded in the simulation program from an $m$-file by pressing the Setup button in the main window shown in Fig. 6.

The obtained results are saved in mat-type data files. The results can be plotted in various forms in MATLAB ${ }^{\circledR}$ upon the request of the user.

The sample generator (of AST 1129284 type) used for the simulations had the following main data: $3 \mathrm{~kW}$ rated power, $220 / 380 \mathrm{~V}(\Delta / \mathrm{Y})$ rated voltage, 11.4/6.61 $\mathrm{A}(\Delta / \mathrm{Y})$ rated current and $1430 \mathrm{~min}^{-1}$ rated speed.

Using the experimental results of several laboratory tests performed in our laboratories the main parameters of the induction machine in discussion were computed. Also these laboratory measurements were used to validate the mathematical model described in detail in section III [15].

The above presented simulation program was used to analyze several dynamic regimes of the given electrical power generation system.

As our future researches in this field will be focused on the advanced control of the doubly fed induction generators used in wind power plants first we studied the effects of the wind speed, and of the imposed rotor voltage.

From the numerous results obtained during our study here only a single set will be presented, that obtained in the case of the imposed voltage of the converter:

$$
U^{*}=120 \sin \left(100 \pi t+\frac{5 \pi}{2}\right) \mathrm{V}
$$

The main results are given in Fig. 7, where the stator and rotor voltages and currents (for only a single phase of the machine), respectively the active and reactive power generated are plotted versus time.
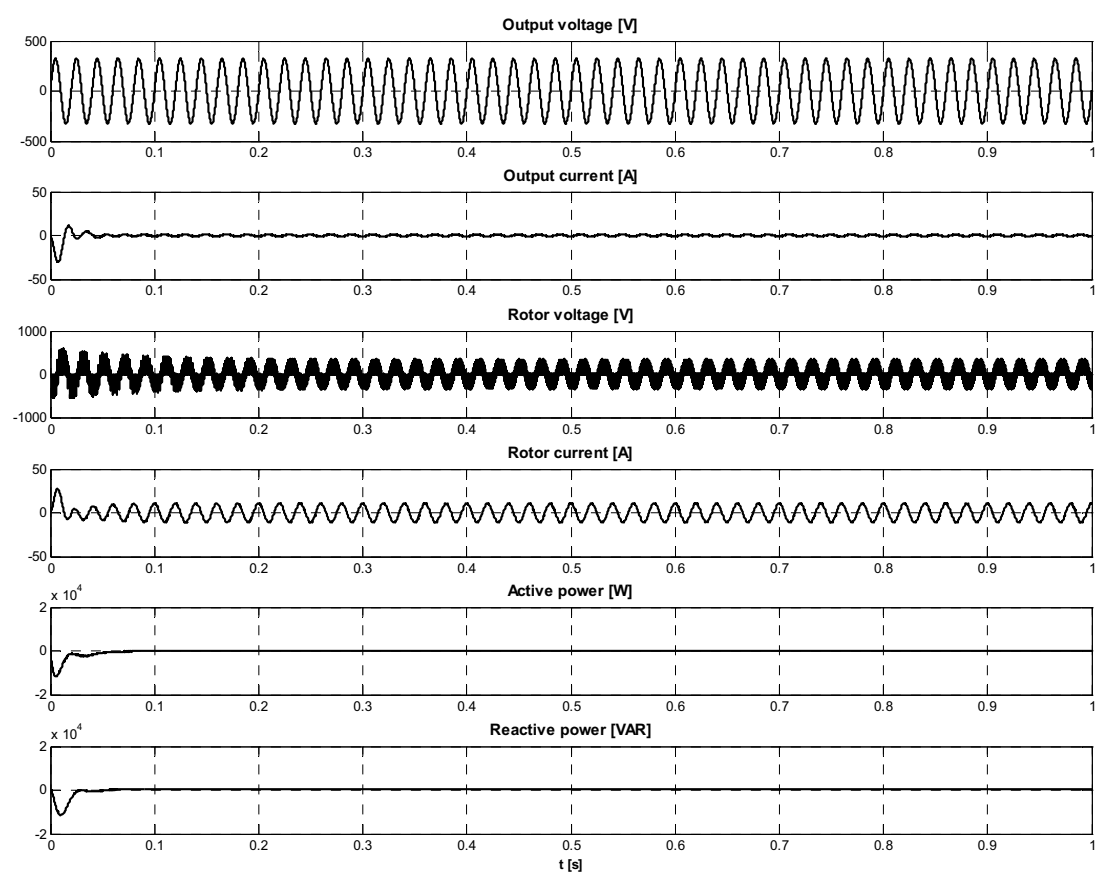

Fig. 7. The main results of the simulation 
It seemed to be also of interest to present some results concerning the converters. Therefore in Fig. 8 the amplitude of the imposed voltage, the output of the saw teeth waveform generator and of the converter, respectively the current through the dc link of the converter are plotted versus time.

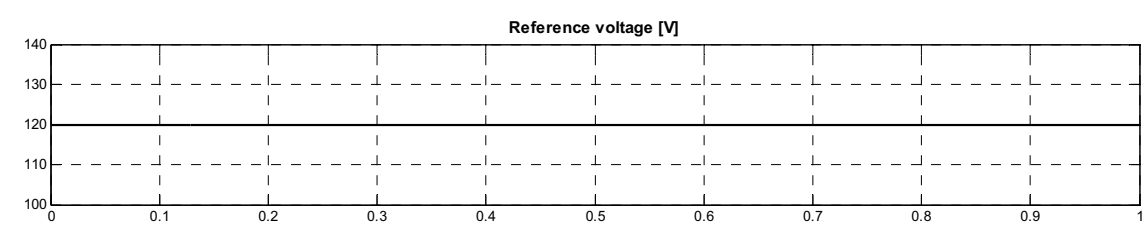

Voltage of the sawteeth-waveform generator [v]
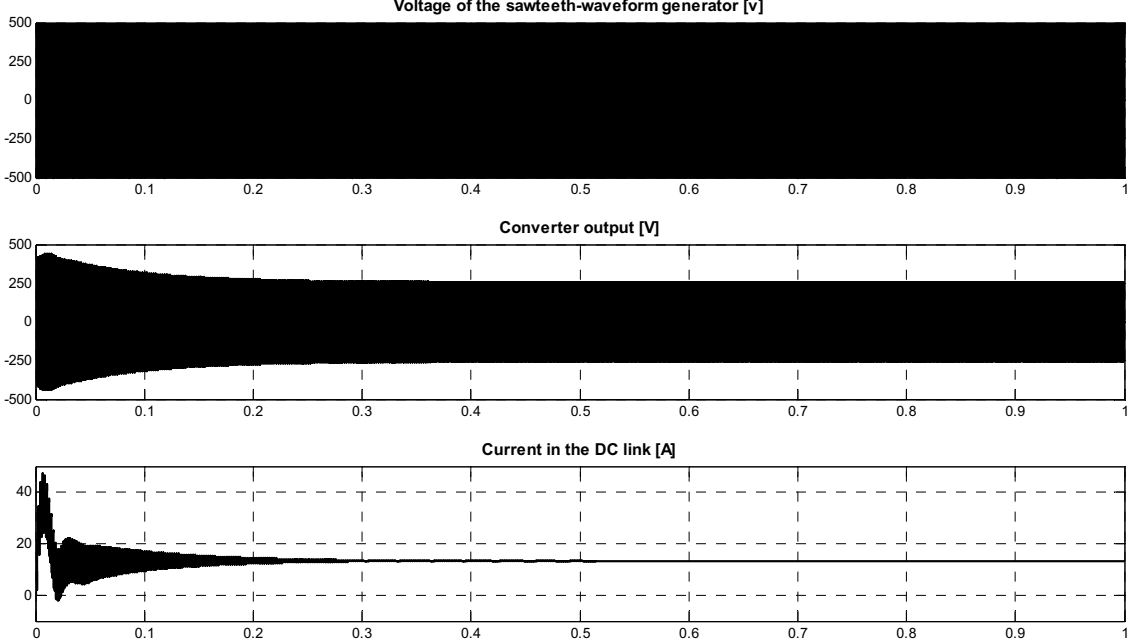

Fig. 8. The variation of the converter's main quantities

For better understanding in Figs. 9 and 10 zoomed views (for a $0.05 \mathrm{~s}$, respectively $0.01 \mathrm{~s}$ period) of the
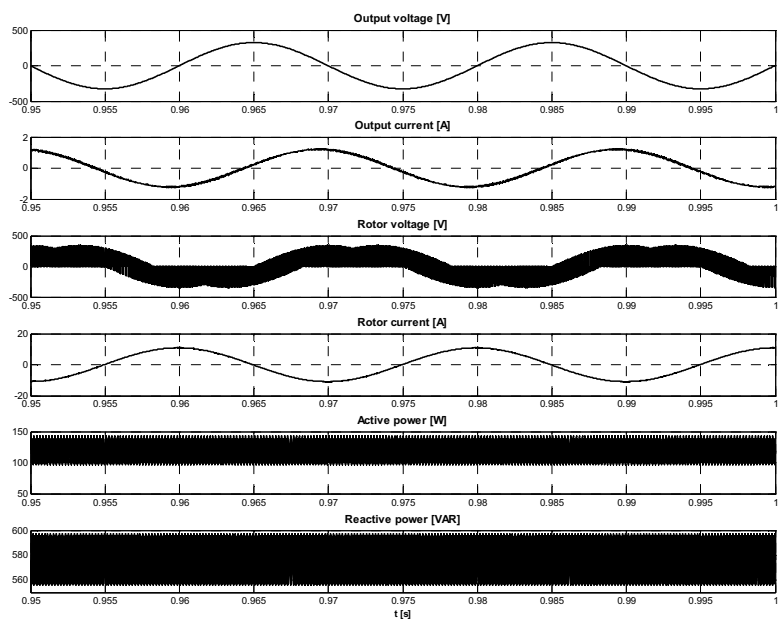

Fig. 9. A zoomed view of Fig. 7

As it can be seen in the above figures both the stator and rotor currents have a sinusoidal waveform. The rotor voltage waveform is chopped due to the inverter. In Fig. 10 the way as the output of the converter is connected between the two polarities of the dc link is well emphasized.

In the simulated conditions the doubly fed induction machine was delivering to the grid in steady-state regime the following active, respectively reactive power:

$$
\begin{gathered}
P=132 \mathrm{~W} \\
Q=568 \mathrm{VAR}
\end{gathered}
$$

which means a power factor of 0.22 . variation of the quantities given in Figs. 7 and 8 are shown.
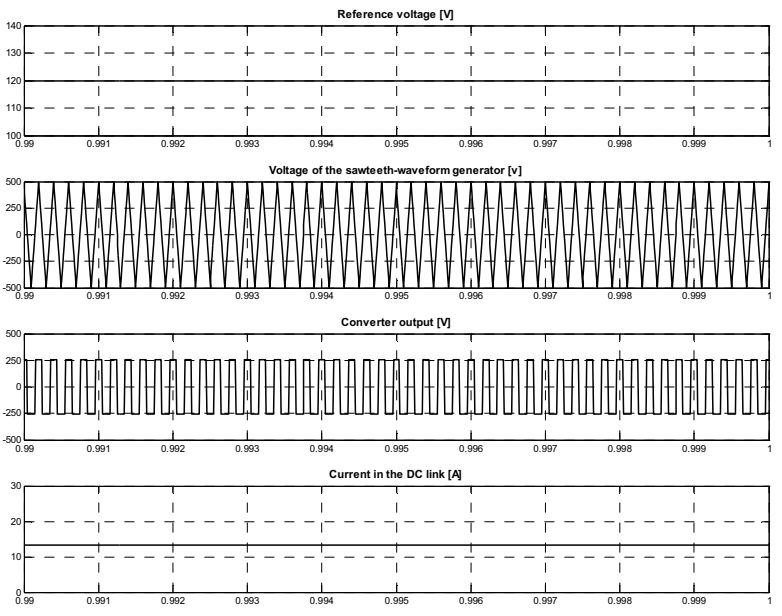

Fig. 10. A zoomed view of Fig. 8

\section{CONCLUSIONS}

Due to its many advantages such as the improved power quality, high energy efficiency and controllability, etc. the variable speed wind turbine using a doubly fed induction generator become a popular concept in the framework of clean energy generation and thus its modeling and simulation is an interesting research topic.

It was proved by dynamic simulations that by changing the imposed signal of the converter coupled in the rotor circuit of the induction machine (which adjusts practically the switching of the semiconductor devices of 
the converters) the power flow between the rotor circuit and the supply can be controlled both in magnitude and in direction [14], [16].

The built up advanced simulation program will be of real help in the future activities of our research team when a control system for the doubly fed induction generator used in wind power plants will be designed. The control system will ensure the independent control of the active and reactive electrical power generated by the induction generator.

The simulation program presented in this paper also will be useful both in undergraduate and master level electrical engineering education.

\section{ACKNOWLEDGEMENT}

The work was possible due to the support given by the Romanian National Council of Scientific Research in Higher Education.

The authors should like to sincerely thank this way for the financial support.

\section{REFERENCES}

[1] "A Wind Energy Pioneer: Charles F. Brush," Danish Wind Industry Association, Copenhagen (Denmark), 2003. URL: http://www.windpower.org/en/pictures/brush.htm.

[2] "The Wind Energy Pioneer - Poul la Cour," Danish Wind Industry Association, Copenhagen (Denmark), 2003. URL: http://www.windpower.org/en/pictures/lacour.htm.

[3] Johnson, G.L., "Wind Energy Systems," Electronic Edition, Manhattan (USA), 2004.

[4] Wind Power Installed in Europe by End of 2006 (Cumulative)," European Wind Energy Association (EWEA), Brussels (Belgium), 2007. URL: http:// www.ewea.org/fileadmin/ewea documents/documents/ publications/statistics/070129 Wind map 2006.pdf.

[5] "Global wind energy markets continue to boom - 2006 another record year," Press release of Global Wind Energy Council (GWEC), Bruxelles (Belgium), 02.02.2007. URL: http://www.gwec.net/uploads/media/07-02_PR_Global Statistics 2006.pdf

[6] Spahić, E., and Balzer, G., "Control Possibility for Offshore Wind Farms", Proceedings of the Power System
Computation Conference (PSCC '2005), Liege (Belgium), on CD: 33_3.pdf, 2005.

[7] Marvik, J.I., Bjørgum, T., Næss, B.I., Undeland, T.M., and Gjengedal, T., "Control of a Wind Turbine with Doubly Fed Induction Generator after Transient Failures," Proceedings of the Nordic Workshop on Power and Industrial Electronics (NORPIE'2004), Trondheim (Norway), on CD: 020.pdf, 2004.

[8] Morren, J., and de Haan, S.W.H., "Short-Circuit Current of Wind Turbines with Doubly Fed Induction Generator," IEEE Transactions on Energy Conversion, vol. 22, no. 1 (March 2007), pp. 174-180.

[9] Polinder, H., van der Pijl, F.F.A., de Vilder, G.J., and Tavner, P.J., "Comparison of Direct-Drive and Geared Generator Concepts for Wind Turbines," IEEE Transactions on Energy Conversion, vol. 21, no. 3 (September 2006), pp. 725-733.

[10] Morren, J., and de Haan, S.W.H., "Ridethrough of wind turbines with doubly-fed induction generator during a voltage dip," IEEE Transactions on Energy Conversion, vol. 20, no. 2 (June 2005), pp. 435-441.

[11] Müller, S., Deicke, M., and de Doncker, R.W., "Doubly Fed Generator Systems for Wind Turbines," IEEE Industry Applications Magazine, May-June 2002, pp. 26-33.

[12] Bélanger, J., and Dufour, C., "Real-Time Simulation of Doubly Fed Induction Generator for Wind Turbine Applications," Technical Paper no. 100, Opal-RT Technologies Inc., Montreal (Canada), 2005. URL: http://www.rt-lab.com/sec_files/dufour_windturbine paper2004.pdf.

[13] Ong, C.-M., "Dynamic Simulation of Electric Machinery Using Matlab/Simulink," Prentice Hall PTR, Upper Saddle River (USA), 1997.

[14] Lei, Y., Mullane, A., Lightbody, G., and Yacamini, R., "Modeling of the Wind Turbine with a Doubly Fed Induction Generator for Grid Integration Studies," IEEE Transactions on Energy Conversion, vol. 21, no. 1 (March 2006), pp. 257-264.

[15] Szabó, L., Biró, K.Á., Cosmina, N., and Jurca, F., "Dynamic Simulation of Induction Generators Coupled to Wind Turbines," Proceedings of the $11^{\text {th }}$ IEEE International Conference on Intelligent Engineering Systems (INES '2007), Budapest (Hungary), 2007, in print.

[16] Sun, T., Chen, Z., and Blaabjerg, F., "Flicker Study on Variable Speed Wind Turbines with Doubly Fed Induction Generators," IEEE Transactions on Energy Conversion, vol. 20, no. 4 (December 2005), pp. 896-905. 